\title{
Avaliação da contaminação de hortas produtoras de verduras após a implantação do sistema de fiscalização em Ribeirão Preto, SP
}

\author{
Evaluation of the contamination of lettuce crops after the establishment \\ of the monitoring system in Ribeirão Preto, SP
}

\author{
Osvaldo M. Takayanagui ${ }^{1}$, Divani M. Capuano ${ }^{2}$, Carlos A. D. Oliveira ${ }^{3}$, \\ Alzira M.M. Bergamini' ${ }^{2}$ Madalena H.T. Okino ${ }^{2}$, Ana A.M.C. Castro e Silva ${ }^{4}$, \\ Maria A. Oliveira ${ }^{2}$, Eliana G.A. Ribeiro ${ }^{2}$ e Angela M.M. Takayanagui ${ }^{5}$
}

\begin{abstract}
RESUMO
O estudo avaliou a contaminação microbiológica e parasitológica de 88 hortas produtoras de verduras, das quais 47 haviam sido investigadas anteriormente. A taxa de contaminação foi de 38,3\% nas hortas previamente investigadas e de 43,9\% nas novas hortas. A segurança alimentar requer um contínuo e eficiente sistema de vigilância sanitária das hortas.
\end{abstract}

Palavras-chaves: Horta. Verdura. Água de irrigação. Segurança alimentar. Cisticercose. Parasitas.

\section{ABSTRACT}

This study evaluated the microbiological and parasitological contamination of 88 market gardens producing green vegetables, of which 47 had been investigated previously. The contamination rate was 38.3\% in the market gardens previously evaluated and $43.9 \%$ in the new market gardens. Food safety requires a continuous and efficient sanitary surveillance system for market gardens.

Key-words: Market garden. Green vegetable. Irrigation water. Food safety. Cysticercosis. Parasites.

A contaminação de alimentos constitui um sério problema de saúde pública. Segundo o Centers for Disease Control and Prevention (CDC $)^{4}$, entre as principais causas do aumento das doenças transmitidas por alimentos, está a mudança dos hábitos alimentares com a preferência pelos alimentos frescos e in natura ${ }^{4}$. Dentro das ações do Programa de Controle da Cisticercose de Ribeirão Preto, SP, a Secretaria Municipal da Saúde implantou a fiscalização das condições higiênico-sanitárias das hortas ${ }^{12}$. 0 objetivo deste estudo foi avaliar a contaminação microbiológica e parasitológica de hortas produtoras de verduras de Ribeirão Preto, SP, na vigência da fiscalização.

No período de fevereiro de 2000 a setembro de 2001, foram colhidas, pela Vigilância Sanitária Municipal, 103 hortaliças e suas respectivas águas de irrigação provenientes de 88 hortas produtoras de verduras. Destas, 47 hortas já haviam sido avaliadas em estudos anteriores e 41 não tinham sido submetidas a qualquer análise prévia. Amostras da água de irrigação foram recolhidas em frascos esterilizados de $250 \mathrm{~mL}$ para a análise microbiológica. Para a investigação parasitológica, foram coletados 2 litros em frascos limpos. Foi também realizada a coleta aleatória de 2 pés de verduras de folha do canteiro, preferencialmente a alface (Lactuca sativa) ou, na sua ausência outra hortaliça folhosa. As verduras foram acondicionadas individualmente em sacos plásticos de primeiro uso, sem contato manual. A análise microbiológica das hortaliças foi fundamentada na determinação do número mais provável $(\mathrm{NMP} / \mathrm{g})$ de coliformes a $45^{\circ} \mathrm{C}$ e na pesquisa de Salmonella spp, de acordo com APHA ${ }^{2}$. A contagem de coliformes a $45^{\circ} \mathrm{C}$ foi realizada em 67 amostras de hortaliças. A análise parasitológica da hortaliça foi realizada segundo Marzochi ${ }^{8}$ com modificações de acordo com Takayanagui e cols ${ }^{12}$. A água

1. Departamento de Neurologia, Faculdade de Medicina de Ribeirão Preto, Universidade de São Paulo, Ribeirão Preto, SP. 2. Laboratório I de Ribeirão Preto, Instituto Adolfo Lutz, Ribeirão Preto, SP. 3. Divisão de Vigilância Sanitária, Secretaria da Saúde do Município de Ribeirão Preto, Ribeirão Preto, SP. 4. Divisão de Vigilância Epidemiológica, Secretaria da Saúde do Município de Ribeirão Preto, Ribeirão Preto, SP. 5. Disciplina de Saúde Pública, Escola de Enfermagem de Ribeirão Preto, Universidade de São Paulo, Ribeirão Preto, SP.

Apoio financeiro: Conselho Nacional de Desenvolvimento Científico e Tecnológico (CNPq) - OMT (Proc. \# 305553/2006-2).

Endereço para correspondência: Dr. Osvaldo M. Takayanagui. Dept ${ }^{\underline{0}}$ Neurologia/FMRP/USP. Av. Bandeirantes 3900, 14048-900 Ribeirão Preto, SP.

Tel: $55163602-2472$

e-mail: otakay@rnp.fmrp.usp.br

Recebido para publicação em 28/8/2005

Aceito em 23/3/2007 
de lavagem das hortaliças foi deixada em repouso em cálices cônicos por 24 horas após filtragem em gaze de 8 dobras. As águas de irrigação foram homogeneizadas e transferidas para cálices cônicos de vidro, deixando-se sedimentar por no mínimo 24 horas. Os sedimentos obtidos foram analisados ao microscópio óptico por exame direto e após centrífugo-flutuação em sulfato de zinco $(\mathrm{d}=1.180)$. Na análise microbiológica da água de irrigação, foi avaliado o NMP de coliformes a $45^{\circ} \mathrm{C} / 100 \mathrm{~mL}$, de acordo com $\mathrm{APHA}^{3}$. A análise estatística foi baseada no teste de McNemar para amostras correlacionadas, adotando $\mathrm{p} \leq 0,05$ como nível de significância.

A presença de coliformes a $45^{\circ} \mathrm{C}$, Salmonella e/ou parasitas foi detectada em 36 (40,9\%) das 88 hortas produtivas. Das 103 águas de irrigação analisadas, 16 (15,5\%) estavam em desacordo com a legislação em vigor ${ }^{5}$, sendo que em 3 (2,9\%) delas foi observada a presença simultânea de parasitas considerados patogênicos para 0 homem. Dentre as 67 hortaliças, nas quais foi realizada a pesquisa de coliformes a $45^{\circ} \mathrm{C}$, em 28 (41,8\%) os níveis encontravam-se acima de $200(\mathrm{NMP} / \mathrm{g})^{6}$. Em apenas uma amostra, foi isolada Salmonella panama. Em 15 (14,6\%) das 103 hortaliças foram detectados simultaneamente, parasitas considerados patogênicos para o homem (cistos de Entamoeba spp e de Giardia spp e ovos de ancilostomídeos, de Ascaris spp e de Trichuris spp). A presença de cistos de Entamoeba spp e de ovos de ancilostomídeos foi valorizada somente em concomitância a uma concentração igual ou superior a $200(\mathrm{NMP} / \mathrm{g})$ de coliformes a $45^{\circ} \mathrm{C}$.

A Tabela 1 apresenta o resultado das análises microbiológica e parasitológica em 18 (38,3\%) das 47 hortas avaliadas em estudos

Tabela 1- Distribuição de bactérias e parasitas encontrados em 18 das 47 hortas produtoras de verduras avaliadas anteriormente. Município de Ribeirão Preto, SP.

\begin{tabular}{|c|c|c|c|c|}
\hline \multirow[b]{2}{*}{$\begin{array}{l}\text { Tipo de } \\
\text { verdura }\end{array}$} & \multicolumn{2}{|c|}{ Verdura } & \multicolumn{2}{|c|}{ Água de irrigação } \\
\hline & $\begin{array}{c}\text { Exame } \\
\text { microbiológico } \\
\text { Coliformes a } 45^{\circ} \mathrm{C} \\
(\mathrm{NMP} / \mathrm{g})\end{array}$ & $\begin{array}{c}\text { Exame } \\
\text { parasitológico } \\
\text { C }\end{array}$ & $\begin{array}{c}\text { Exame } \\
\text { microbiológico } \\
\text { Coliformes a } 45^{\circ} \\
(\mathrm{NMP} / \mathrm{mL})\end{array}$ & $\begin{array}{l}\text { Exame } \\
\text { parasitológico } \\
{ }^{\circ} \mathrm{C}\end{array}$ \\
\hline Rúcula & 336 & Ent, Ancy & adequado & negativo \\
\hline Alface & 2.860 & negativo & adequado & negativo \\
\hline Alface & 2.970 & Ent & adequado & negativo \\
\hline Alface & 828 & negativo & 1.600 & negativo \\
\hline Almeirão & 204,6 & negativo & 5.400 & negativo \\
\hline Almeirão & 576 & Ascaris spp, Ent & adequado & negativo \\
\hline Alface & 1.760 & Ancy, Giardia spp & adequado & negativo \\
\hline Alface & 1.540 & negativo & adequado & negativo \\
\hline Alface & $>4.080$ & Ent, Trichuris spp & adequado & negativo \\
\hline Alface & 432 & Ancy, Giardia spp & adequado & negativo \\
\hline Almeirão & 480 & Ancy, Giardia spp & adequado & negativo \\
\hline Almeirão & 690 & negativo & 2.200 & negativo \\
\hline Alface & 2.420 & negativo & 5.400 & negativo \\
\hline Alface & adequado & negative & 1.700 & negativo \\
\hline Alface & 735 & Ent, Giardia spp & $\geq 2.400$ & Ent, Giardia spp \\
\hline Alface & $>2.400$ & Ent, Ancy & 16.000 & Ent, Ancy \\
\hline Alface & 736 & negativo & adequado & negativo \\
\hline Alface & NR & negativo & 5.400 & negativo \\
\hline
\end{tabular}

Ent: Entamoeba sp; Ancy: ancilostomídeos; NR: não realizado anteriores. Na Tabela 2, estão os resultados encontrados nas $18(43,9 \%)$ das 41 hortas sem avaliações prévias.

Tabela 2 - Distribuição de bactérias e parasitas encontrados em 18 das 41 hortas produtoras de verduras sem avaliações prévias. Município de Ribeirão Preto, SP.

\begin{tabular}{|c|c|c|c|c|}
\hline \multirow[b]{2}{*}{$\begin{array}{l}\text { Tipo de } \\
\text { verdura }\end{array}$} & \multicolumn{2}{|c|}{ Verdura } & \multicolumn{2}{|c|}{ Água de irrigação } \\
\hline & $\begin{array}{c}\text { exame } \\
\text { microbiológico } \\
\text { coliformes a } 45^{\circ} \mathrm{C} \\
(\mathrm{NMP} / \mathrm{g})\end{array}$ & $\begin{array}{c}\text { exame } \\
\text { parasitológico }\end{array}$ & $\begin{array}{c}\text { exame } \\
\text { microbiológico } \\
\text { coliformes a } 45^{\circ} \mathrm{C} \\
(\mathrm{NMP} / \mathrm{mL})\end{array}$ & $\begin{array}{c}\text { exame } \\
\text { parasitológico }\end{array}$ \\
\hline Alface & $>5.760$ & negativo & adequado & negativo \\
\hline Almeirão & adequado & negativo & 1.600 & negativo \\
\hline Alface & 792 & Giardia spp & adequado & negativo \\
\hline Alface & $>3.840$ & negativo & adequado & negativo \\
\hline Almeirão & $>4.320$ & Ascaris spp & adequado & negativo \\
\hline Alface & 240 & negativo & adequado & negativo \\
\hline Alface & $>4.560$ & Ascaris spp & adequado & negativo \\
\hline & & Ancy, Ent & & \\
\hline Alface & 460 & Ent & 5.400 & Ent \\
\hline Alface & 504 & negativo & adequado & negativo \\
\hline Alface & 1.870 & negativo & 3.500 & negativo \\
\hline Alface & 828 & negativo & adequado & negativo \\
\hline Almeirão & 506 & Giardia spp & 9.200 & negativo \\
\hline & & Ent & & \\
\hline Alface & 598 & negativo & adequado & negativo \\
\hline Alface & NR & Ascaris spp & & \\
\hline & Salmonella panama & Ent & adequado & negativo \\
\hline Alface & NR & negativo & 9.200 & negativo \\
\hline Agrião & NR & negativo & 16.000 & negativo \\
\hline Alface & NR & negativo & 5.400 & negativo \\
\hline Almeirão & NR & negativo & 1.300 & negativo \\
\hline
\end{tabular}

Ent: Entamoeba sp; Ancy: ancilostomídeos; NR: não realizado

As doenças transmitidas por alimentos (DTAs) têm recebido atenção cada vez maior em todo o mundo ${ }^{4}$. Entretanto, no Brasil são escassos os trabalhos avaliando a qualidade das verduras coletadas diretamente das hortas ${ }^{10} 12$ e das respectivas águas de irrigaçã $0^{10}$, sendo que a maioria dos estudos refere-se às verduras obtidas nos pontos de venda ${ }^{713}$. Dentre as 67 hortas nas quais houve avaliação concomitante de coliformes a $45^{\circ} \mathrm{C}$ na água e nas hortaliças, $30(44,8 \%)$ apresentaram níveis acima do limite tolerado. Das 21 hortas analisadas de acordo com a legislação em vigor $^{1}, 6$ (28,5\%) apresentaram na água de irrigação, níveis de coliformes $a 5^{\circ} \mathrm{C}$ acima do limite tolerado. A presença simultânea de parasitas foi detectada em 15 (17\%) das 88 hortas avaliadas. Chama a nossa atenção a presença de Giardia spp em uma amostra de água de irrigação, pois os cistos deste protozoário são altamente resistentes às condições adversas do meio ambiente, podendo contaminar a água e os alimentos ${ }^{11}{ }^{14}$.

O presente estudo revelou que $40,9 \%$ do total das hortas analisadas estavam em desacordo com a legislação, tanto nas hortas previamente avaliadas $(38,3 \%)$ como nas investigadas anteriormente $(43,9 \%)$, configurando a não melhora das condições higiênico-sanitárias das hortas produtoras de verduras 
no município de Ribeirão Preto. A existência do sistema de fiscalização das hortas e a presumível conscientização dos produtores quanto às condições higiênicas não foram capazes de evitar a elevada frequiência de contaminação bacteriológica e parasitológica.

Tendo em vista os resultados obtidos neste estudo, ressaltamos a real importância da manutenção de um sistema rigoroso de vigilância sanitária das hortas produtoras de verduras do município, visando uma melhor condição higiênico-sanitária das hortaliças oferecidas à população. Apesar da não constatação de ovos de Taenia sp descrita por Marzochi ${ }^{8}$, e Oliveira \& Germano ${ }^{9}$, a elevada freqüência de contaminação fecal indica o potencial risco de transmissão de ovos da Taenia solium através do consumo de verduras cruas, podendo justificar a alta prevalência da cisticercose no nosso município.

\section{REFERÊNCIAS}

1. Agência Nacional de Vigilância Sanitária. Diário Oficial da União. Ministério da Saúde. Resolução RDC n. 12, 02 de Janeiro de 2001, Seção 1, p.45-53, 2001.

2. American Public Health Association. Technical Committee on Microbiological Methods for Foods. I $n$ : Vanderzant C, Splittstoesser DF (eds) Compendium of methods for the microbiological examination of foods. 3rd edition, American Public Health Association, Washington p. 336-335, 1992.

3. American Public Health Association. Standard methods for the examination of water and wastewater. $19^{\text {th }}$ edition, American Public Health Association, Washington. Microbial Examination. Cap. 9, p. 44-50, 1995.

4. Centers for Disease Control and Prevention. Diagnosis and management of foodborne illnesses: a primer for physicians. Morbidity and Mortality Weekly Report 53 (RR-4):1-33, 2004.
5. Centro de Vigilância Sanitária. Portaria n. 21 de 19 de Dezembro de 1991. Diário Oficial do Estado, São Paulo, 24 de Dezembro de 1991.

6. Divisão Nacional de Vigilância Sanitária de Alimentos da Secretaria Nacional de Vigilância Sanitária. Diário Oficial da União, Portaria n. 451 de 19 de Setembro de 1997, Seção I, p. 4-13, 1998.

7. Guimarães AM, Alves EGL, Figueiredo HCP, Costa GM, Rodrigues LS. Frequência de enteroparasitas em amostras de alface (Lactuca sativa) comercializadas em Lavras, Minas Gerais. Revista da Sociedade Brasileira de Medicina Tropical 36:621-623, 2003

8. Marzochi MCA. Estudo epidemiológico da poluição por enteroparasitas em áreas de horticultura da cidade de Ribeirão Preto, SP, Brasil. Tese de Doutorado, Universidade Estadual de Londrina, PR, 1974.

9. Oliveira CAF, Germano PML. Estudo da ocorrência de enteroparasitas em hortaliças comercializadas na região metropolitana de São Paulo, SP, Brasil. I- Pesquisa de helmintos. Revista de Saúde Pública 26:283-289, 1992.

10. Simões M, Pizani B, Marques EGL, Prandi MAG, Martini MH, Chiarini PFT, Antunes JLF, Nogueira AP. Hygienic-sanitary conditions of vegetables and irrigation water from kitchen gardens in the municipality of Campinas, SP. Brazilian Journal of Microbiology 32:331-333, 2001.

11. Slifko TR, Smith HV, Rose JB. Emerging parasite zoonoses associated with water and food. International Journal for Parasitology 30:1379-1393, 2000.

12. Takayanagui OM, Febrônio LH, Bergamini AM, Okino MH, Castro e Silva AA, Santiago R, Capuano DM, Oliveira MA, Takayanagui AMM. Fiscalização de hortas produtoras de verduras no município de Ribeirão Preto, SP. Revista da Sociedade Brasileira de Medicina Tropical 33:169-174, 2000.

13. Takayanagui OM, Oliveira CD, Bergamini AMM, Capuano DM, Okino MHT, Febrônio LHP, Castro e Silva AAMC, Oliveira MA, Ribeiro EGA, Takayanagui AMM. Fiscalização de verduras comercializadas no município de Ribeirão Preto, SP. Revista da Sociedade Brasileira de Medicina Tropical 34:37-41, 2001.

14. Thompson RC, Monis PT. Variation in Giardia: implications for taxonomy and epidemiology. Advances in Parasitology 58:69-137, 2004. 